\title{
Covid-19: doctors are warned not to go public about PPE shortages
}

\author{
Clare Dyer
}

The BMJ

As hospitals run out of personal protective equipment (PPE) for frontline healthcare staff fighting the covid-19 pandemic, doctors report that trusts and NHS England are clamping down on their attempts to go public about the situation in mainstream news outlets or on social media.

After some trusts warned that they might have no fluid repellent gowns left, NHS England said staff might need to use alternatives, such as plastic aprons with coveralls. ${ }^{1}$

More than 50 healthcare workers have died from covid-19 and the lobbying group Doctors' Association UK (DAUK) has set up an app, www.nhsppe.com, for doctors anonymously to report their concerns about shortages of gowns and masks to protect them from infection.

But many are also reporting attempts to stop them speaking to the media about their fears. One consultant wrote of "a general email from the trust, then personal advice, that social media is being monitored and to be careful."

A junior doctor mentioned "an email saying we should not be posting 'inappropriate' social media comments or posts regarding the state of PPE." Another wrote, "We are emailed daily to avoid speaking to anyone in the press or social media as a part of daily covid briefing."

Another consultant reported, "I have been forbidden by my trust from posting anything about conditions on social media as my name could link back to my trust. Please keep championing this, you may literally be saving our lives."

A GP wrote of being advised by the local clinical commissioning group not to give an interview to a journalist about PPE. "When I told the journalist this, she said lots of doctors have said the same thing. It's like we've all been told not to speak to the media to give the true situation," they said.

Norfolk and Suffolk NHS Foundation Trust, in a newsletter seen by the local paper, the East Anglian Daily Times, has told staff to avoid tweeting about "political issues, such as PPE, testing, and exit strategies.”

Jenny Vaughan, a consultant neurologist and "learn not blame" lead at DAUK, said, "We've been approached by many doctors who have been warned off raising concerns about lack of PPE and been told not to speak to the press. Bullying of staff when they speak out about safety is completely unacceptable. Doctors and nurses on the frontline have a right to speak out if they or their families or patients could be at risk."
Katie Sanderson, who works in acute medicine, has spoken on BBC Radio 4's Today and in the print media about her experience of treating patients with covid-19 at a London hospital. "Masses of people" don't have enough PPE, she told The BMJ. "If people don't talk about it, how can they put it right?"

Sanderson said she was not in a training programme and didn't feel vulnerable in speaking to the media. "But many of the friends I've asked for an interview have said no. My sense is that many people are afraid of what the consequences of speaking up may be for them and do not want to stick their heads above the parapet."

Nishant Joshi, a junior doctor in emergency medicine, has done several print and broadcast media interviews. "After my initial Guardian interview was entitled 'Everyone is scared to speak out,' it was perhaps inevitable that I would be shown exactly why this would be the case," he said.

"Gentle phone calls ensued, mostly from my hospital's friendly communications managers. We came to a gentlemen's agreement that I would avoid mentioning the hospital where I worked. These phone calls arguably became less friendly when I was inadvertently introduced by a host on a BBC show as being from hospital X."

The communications lead for one NHS trust told The BMJ that NHS England was more involved in decisions about media access than it would be in "normal" times. "If a doctor came to me and said they wanted to do an interview, the expectation would be that they would seek approval. It's a much more command and control situation than we are used to in normal times, but these are not normal times."

Paul Daniels, a solicitor at Keystone Law who is on a panel of lawyers for the whistleblowing charity Protect, said doctors and other healthcare workers should be cautious about taking their concerns to the media.

"Worried healthcare and key workers may consider reporting PPE concerns to NHS England, to their union in confidence, or to their MP. Reporting matters directly to the media can be risky and lead to a backlash. Only in exceptional cases will such conduct be considered protected 'whistleblowing' under UK laws."

Protect advises healthcare workers, "If you are considering contacting a journalist or raising concerns in a social media post, either contact us at Protect on 02031172520 or send us 
an email through our contact online form, protect-advice.org. uk/contact-protect-advice-line."

\section{\#properPPE}

The BMSS \#properPPE campaign is calling for healthcare workers on the front line to be given the appropriate level of PPE. We are calling for doctors to have the correct PPE for each clinical setting, for PPE of sufficient quality and quantity, and for doctors to be given what they need to make them feel safe.

Share your stories with us on social media by using \#properPPE or by email at newsdesk@bmj.com. We want to hear about your experiences so that we can push governments to act.
1 Rimmer A. Covid-19: Experts question guidance to reuse PPE. BMJ 2020;369:m157710.1136/bmj.m1577.

Published by the BMJ Publishing Group Limited. For permission to use (where not already granted under a licence) please go to http://group.bmj.com/group/rights-licensing/ permissions 